\title{
Beyond the Classroom: From Education for Rural Transformation to Learning Within Rural Transformation?
}

\author{
Anna-Robinson Pant* \\ School of Education and Lifelong Learning, University of East Anglia, United \\ Kingdom
}

\begin{abstract}
Much research and policy has focused on improving the performance and reach of formal educational institutions in rural areas. Debates within education and development have been largely concerned with analysing the relationship between different levels of schooling and various indicators of well-being. Such research has usually been framed within an economistic discourse: associating education and learning primarily with schools and formal providers, and assuming that only formally educated people can facilitate development and rural transformation. This limited starting point has led to privileging investigation into formal learning and to a neglect of alternative lenses for researching people's everyday learning in rural areas. Drawing on the methodology and findings of an IFAD-UNESCO project, this article proposes an alternative approach to researching and theorising learning in rural areas. In place of focusing on formal education and educational providers, the study team conducted ethnographicstyle research on how young people learned skills and knowledge informally and exploring the relationship between informal, non-formal and formal learning. The findings challenged many assumptions around a linear 'literacy first' and teacher-centred model of development, revealing that so-called 'illiterate' people had often developed their own innovative strategies for learning new skills,
\end{abstract}


such as mobile phones. The paper concludes by reflecting on the implications of this research study for educational researchers, policy makers and practitioners seeking to develop greater understanding of the complex relationship between education and rural livelihoods.

Keywords: Rural transformation, adult learning, adult literacy, ethnography, informal learning

\section{Introduction}

Much research and policy has focused on improving the performance and reach of formal educational institutions in rural areas. Debates within education and development have been largely concerned with analysing the relationship between different levels of schooling and various indicators of well-being (such as nutrition, child and maternal health, see UNESCO, 2014a); differences in access and retention between girls and boys, indigenous and majority groups; and evaluating curricula in rural schools in terms of employment outcomes. Such research has usually been framed within an economistic discourse which focuses on inputs and measurable outcomes: associating education and learning primarily with schools and formal providers, and assuming that only formally educated people can facilitate development and rural transformation. The 2030 Sustainable Development agenda (United Nations [UN], 2015) may continue the earlier decade's Education For All emphasis on formal schooling, though recent policy discussions have indicated the importance of turning attention from enhancing access towards ensuring the quality of education provided. The UNESCO EFA Global Monitoring Report, Teaching and Learning: Achieving Quality for All (UNESCO, 2014a) suggests that considerations of quality will still focus on inputs (notably teachers) and assessment of outcomes, with little consideration of questions around curriculum and learning.

This limited starting point - where 'education' is considered synonymous with 'schooling' - has led to privileging investigation into formal education and to a neglect of alternative lenses for researching people's everyday learning in rural areas. The assumption has been that education takes place in formal settings and institutions in a highly structured and predictable form. Looking back at my first experiences in Nepal as a volunteer teacher trainer with the Seti Project (Education for Rural Development Project in Seti Zone) in the 1980s, I realise that we viewed education largely in terms of formal learning: whether teacher training, adult literacy courses or vocational skill programmes. We also believed 
that rural transformation (or 'rural development' as it was then termed) could be facilitated through adapting the school curriculum to respond to young people's experiences in this remote region (Bajhang, Bajura and Doti in Far Western Nepal) and encouraging previously excluded groups, particularly women and young girls, to join non-formal education programmes. We used the language and teaching approaches of Freire, aiming to facilitate 'critical consciousness' through the literacy classes, challenging the common idea that learners were 'empty vessels' and building instead on learners' experiences. However, there was a certain contradiction in the project's strong message that rural transformation was going to be initiated by this innovative approach to education, promoted by foreign donors. Looking back at my early experiences with the Seti project, I can see that we did not take account of the ways in which rural transformation was already taking place and the role that informal learning played within those social, political and economic processes.

In rural communities around the world, people have long recognised the power of informal learning to transform their lives and have developed their own strategies for sharing and adapting indigenous and new knowledge with their peers and family members to improve their livelihoods. With the arrival and greater spread of digital technologies - particularly mobile phones - young people are now exploring new ways of learning within their communities. Intergenerational learning is not just about young people learning traditional skills from their parents, but also about older generations learning how to use new technologies from their children. Rural transformation is taking place in ways rarely

envisaged a decade before - and the challenge for educational providers is how to engage with and respond to these changes effectively. Though some recent studies have explored how rural people are using new technologies for educational purposes, the findings and recommendations tend to assume a formal model of education. For instance, a recent report on mobile reading in seven countries in the South proposes one-day seminars to introduce mobile reading (UNESCO, 2014b, p. 79). Much educational policy for rural transformation has been influenced by a linear approach to education and development (based on Human Capital Theory). The assumption is that only literate and formally educated people can facilitate and participate in development processes. Research evidence such as Lockheed Jamieson, and Lau's (1980) finding that four years of education makes a difference to farmer productivity has been used to support this 'literacy first' and 


\section{A. Robinson-Pant}

'schooling first' model of development. This prioritisation of formal education has led to a lack of acknowledgement of how informal learning can complement and support formal learning.

Given this powerful discourse, this paper sets out to investigate how educational researchers and policy makers could move beyond the classroom to respond to informal learning and rural transformation in rural communities. From visiting Nepal over the past thirty years, I am increasingly aware of the unpredictable ways in which rural economies are being rapidly transformed which are viewed as negative by some, positive by others. I suspect that this rural transformation has less to do with formal education and much more to do with the expanding communication infrastructure, changing economic landscape and political mobilisation. Within this complex picture, informal learning plays an important part in influencing who loses and wins from new opportunities. Yet educational debates in Nepal and elsewhere continue to focus almost exclusively on formal education, with the result that a disconnect between formal and informal learning in many rural communities seems to be more apparent now than ever before. This paper is not downplaying the importance of supporting formal learning. Rather, I am arguing that without greater understanding into and recognition of informal learning in rural areas, the potential of formal education to promote real social change will be severely constrained.

I am therefore proposing an alternative way of looking at the relationship between education and rural transformation - in contrast to the conventional assumption of 'education for rural transformation' as outlined above. There are two key distinctions to be noted here:

- education is wider than formal and non-formal institutions and programmes; informal and formal learning are intimately connected and people engage in different kinds of informal learning in everyday life

- rural transformation takes place regardless of formal educational institutions and interventions, and rural people (both educated and non-educated) are active players in these political, economic and social processes.

These assumptions formed the starting point of a recent IFAD-UNESCO research project, 'Learning knowledge and skills for agriculture to improve rural livelihoods' (2013-14) which set out to explore how young people learned knowledge and skills informally and to learn more about the relationship between informal, non-formal and formal learning. I will take this project as a case study 
in order to explore how policy-focused research taking an alternative lens on education and rural transformation might begin to influence policy and practice in this area. I will begin by discussing in more detail some of the key concepts informing the project and what I am referring to as an 'alternative' to the dominant paradigm shaping policy and research as described above.

\section{Reconceptualising 'Education for Rural Transformation'}

Understanding and valuing informal learning implies interrogating what we mean by both 'education' and 'rural transformation'. This section introduces alternative lenses for exploring informal learning within and beyond the education sector, and for investigating how rural livelihoods are changing.

\section{Informal Learning and Education}

Recognising that informal learning is an important aspect of education means looking beyond the classroom. We need to investigate not only how people later apply their learning, but also to consider everyday life as a site of learning and how this differs from a formal institution. Definitions of formal, non-formal and informal learning have identified some key characteristics and contrasts: the kind of structure, whether planned (systematic) or incidental (haphazard), differences in purpose (for certification or to learn a skill that is needed now) and the degree of learner control (see Rogers, 2014). An example is the following definition which has informed EU (European Union) policy documents:

Formal learning. Formal learning occurs as a result of experiences in an educational or training institution, with structured learning objectives, learning time and support which leads to certification. Formal learning is intentional from the learner's perspective.

Non-formal learning. Non-formal learning is not provided by an education or training institution and typically does not lead to certification. It is, however, structured (in terms of learning objectives, learning time or learning support). Non-formal learning is intentional from the learner's perspective.

Informal learning. Informal learning results from daily life activities related to work, family or leisure. It is not structured (in terms of learning objectives, learning time or learning support) and typically does not lead to certification. Informal learning may be intentional but in most cases it is non-intentional (or 'incidental'/random).

(European Commission, 2001) 


\section{A. Robinson-Pant}

It can however be problematic to think of informal, formal and non-formal learning as discrete categories and disregard, for instance, informal learning that takes place in formal schools (including the hidden curriculum). Colley et al. (2003) suggest that "it is more accurate to conceive of formality and informality as attributes present in all circumstances of learning" (p. i). A useful conceptualisation is to see informal and formal learning as "lying on a continuum ranging from accidental/incidental learning, through task-conscious learning, through self-directed learning to non-formal and formal learning" (Rogers, 2014, p. 5).

Rather than assuming there is one kind of informal learning (which contrasts with formal and non-formal), Rogers (2014) emphasises that there are many different kinds of informal learning: incidental, task-conscious, self-directed and/ or intentional. Progress in informal learning can be measured by task, such as succeeding in learning to change a car wheel. Tough (1979) used the image of an iceberg to illustrate the relationship of informal learning to formal learning - formal and non-formal learning were represented by the visible part of the iceberg whereas informal learning lies hidden beneath the water. The challenge for researchers and educators is how to understand more about the learning that is often unrecognised by people themselves - Polyani's (1967) notion of tacit knowledge, "that which we know but cannot tell".

The concept of 'situated learning' (Lave \& Wenger, 1991) has informed many studies into how people learn in everyday life, offering insights into informal learning processes in terms of social networks and communities of practice. Rather than assuming an input-output linear model of education where teachers facilitate learning activities using certain resources, the social practice or situated learning approach takes a more holistic perspective on learning and learners to understand how learning is shaped by everyday activities. 'Situated literacies' (Barton, Hamilton, \& Ivanic, 2000) draws on a similar idea of reading and writing as embedded in everyday practices, proposing multiple literacies rather than one universal literacy that is associated with schooling (Street, 1995). This involves looking at how everyone (not just 'literate' people) engages with literacy practices in everyday life and analysing the strategies that non-literate people have developed to learn to process written texts (including digital literacies).

Researching education in rural areas through the theoretical lenses outlined above challenges the traditional hierarchies between formal/informal learning, 
literate/illiterate people and school literacy/everyday literacy. By moving beyond these static binaries, researchers have been able to develop an analysis which can recognise and respond to the ways in which such hierarchies are contested and transformed (for instance, the growing influence of digital literacies at present).

\section{What Do We Mean by 'Rural Transformation'?}

With $70 \%$ of the world's poorest people living in rural areas (International Fund for Agricultural Development [IFAD], 2010), many governments have promoted agriculture as the key to economic improvement and a driver of non-farm activities. As young people make up a significant proportion of the rural population, policy makers have identified formal education as a means to encourage them to stay in rural areas (the notion of 'education for rural transformation'). More often however, young people and their parents see school as offering a possible escape from the rural area, with farming has been regarded by many as 'the occupation of last resort' (Tadele \& Gelle, 2012). Alongside the impact of schooling (and the larger numbers of children now going to school), we need to examine the ways in which rural areas are changing due to globalisation - particularly Foreign Direct Investment (FDI) in land. In many developing countries, foreign investors now rent or own large areas of agricultural land, displacing small landholders and introducing new technologies, crops and systems of management.

Reconceptualising 'rural transformation' implies taking a different starting point to recognise that education is only one factor amongst many others that has influenced change. Rather than focusing on 'education', we need to develop a more holistic perspective on rural transformation, to consider what is being changed to what and how? This could be called an 'education second' approach - in that we begin to consider education in relation to change, rather than as the main or only influence on change. The impact of globalisation means that we have to rethink what we mean by 'local knowledge' and investigate the kinds of knowledge and skills that people are learning in order to survive in rural areas today. There is often a tendency to polarise rural/urban and off-farm/onfarm activities within policy development, in contrast to the realities of people's lives where they may adopt a variety of livelihood strategies over a lifetime. Adopting an alternative lens of multiple and changing livelihoods on rural transformation implies rethinking key concepts like migration, which can be seen as a logical response to changes in the rural economy and infrastructure, as well 
as engagement with new knowledges and values through social and conventional media.

\section{Exploring the Case: IFAD-UNESCO Research Project, 'Learning Knowledge and Skills for Agriculture to Improve Rural Livelihoods' (2013-14)}

The remainder of this paper will draw on the findings and methodology of the IFAD- UNESCO project, 'Learning knowledge and skills for agriculture to improve rural livelihoods' (2013-14), as exemplifying an alternative approach to researching and theorising learning in rural areas.

\section{Aims and Methodology}

In place of focusing on formal education and adopting an entry point through educational providers (particularly schools and formal skill development/adult learning programmes), the study sought to put informal learning centre stage. The IFAD-UNESCO research teams in Cambodia, Egypt and Ethiopia used the concept of 'situated learning' (elaborated by Lave \& Wenger, 1991) and 'situated literacies' (Barton et al., 2000) to conduct ethnographic-style research on young people's learning in six rural communities (two contrasting field sites in each country). They analysed learning in terms of social networks, everyday practices and relationships.

The conceptualisation of 'education' and 'rural transformation' outlined earlier shaped the project methodology in the following ways:

- Following Rogers' (2014) notion of a continuum between informal and formal learning (according to whether learning is planned, intentional, task conscious), informal and formal learning were not considered as discrete or separate. Rather than only considering whether the institution or site of learning was 'formal' or 'informal', a framework based on the idea of a continuum was developed for analysing the kind of learning taking place and how, for instance, informal learning also supported formal learning in school. This focus on learning processes helped the teams to analyse 'situated' literacy and literacy mediation practices, as opposed to assessing literacy outcomes.

- The entry point of the research was to investigate informal learning within agricultural activities and everyday life, (rather than to focus on educational providers or institutions), through participant observation in the field site communities. A distinction was made between agriculture and farming, so 
that a broader perspective could be developed on rural transformation in the field site areas (Foreign Direct Investment was particularly widespread in Ethiopia and Cambodia).

- Policy and providers across a range of sectors were investigated, rather than focusing only on the education sector. This was in recognition that other sectors such as agriculture are also involved in educational activities and may promote different learning approaches and skills (both hard and soft) as compared to the education sector.

- A gendered perspective was developed not only on schooling (e.g. girls' access to schooling) but also to analyse education in relation to livelihood options, risks, gendered identities and gender relations.

- 'Youth' as a category was deconstructed in recognition of their diversity as a group, though recognising the shared aspirations and common experiences of young people in rural areas - such as the notion of youth as a period of 'waithood' (White, 2012).

- Ethnographic-style research was conducted in order to explore young people's experiences and the meanings that they gave to schooling, agriculture and rural transformation. This bottom-up approach to theorisation helped to challenge the research team's starting assumptions - such as education being a 'good thing' in relation to rural transformation or that all young people would want to escape the rural areas.

In collaboration with stakeholders, the research teams selected two contrasting field sites in each of the three countries. Criteria used included: different kinds of agriculture (a lowland pastoralist community and highland mixed agriculture in Ethiopia), districts with high versus low migration or contrasting economic opportunities (Cambodia included a popular tourist area) and communities with differing educational facilities (Egypt).

Ethnographic-style fieldwork was conducted for three weeks in each country and was informed by a literature review based on documentary analysis of national policy and previous research in the area ${ }^{1}$. Given the short time available for fieldwork, we decided it would be more appropriate to term this 'ethnographic-style' research (Green \& Bloome, 1997) than ethnography - which would involve intensive fieldwork (particularly participant observation) over many weeks or months. This is a particularly important distinction to bear in 
mind in terms of theorising from the findings within this journal article: the data was collected primarily to inform policy and practice, rather than to deepen theoretical understanding around informal or situated learning (as might be the aim of an academic research study). It is also worth noting that the partner institutions in Ethiopia (Ethiopian Institute of Agricultural Research of the Federal Democratic Republic of Ethiopia) and Cambodia (Council for Agricultural and Rural Development of the Royal Government of Cambodia) were agricultural research institutes, with greater familiarity with quantitative research methods in agriculture than qualitative educational research. By contrast, the Adult Education Department of Ain Shams University in the Republic of Egypt had extensive experience of conducting ethnographic research on adult learning. My own role on the project was as coordinator to develop the research design, provide training in ethnographic methodology, support the analysis and report writing.

An important aspect of the research design was that workshops with key stakeholders (particularly at Ministry level) were held at various points of the research process in order to share ongoing findings and discuss how these might inform policy directions in the agriculture and education sectors in each country. Although the project could be viewed in certain respects as a comparative study, each team and stakeholders developed the project in relation to their countryspecific policy agenda and to take into account context-specific factors (such as the comparative dimension of the Ethiopian study with regard to pastoralism and mixed farming).

In the next section, I will discuss findings around informal learning and rural transformation that emerged from the project and explore how these led to different kinds of questions around policy and practice. A key debate that arose in all three country contexts was around how to use small-scale qualitative studies such as these to inform national policy, without attempting to generalise statistically from the research data.

\section{Identifying Key Findings and Developing Implications for Policy From the Study}

The overall study findings challenged many assumptions around a linear 'literacy first' (Rogers, 2000) and teacher-centred model of development. The research revealed, for instance, that so-called 'illiterate' people had often developed their own innovative strategies for learning and using mobile phones. 
The study also gave insights into the private sector, such as the ways in which commercial employers supported client-led informal learning, in contrast to the classroom 'one-size-fits-all' approach of many educational providers. By exploring young people's views of education and rural livelihoods, the study also broadened analysis from assessing the immediate economic benefits of education, to investigating perceptions about schooling within these communities (its symbolic value and role in facilitating social change). The study offered understanding into how gendered identities and gender relations shape people's livelihoods, learning and outlook on life. Although these findings greatly influenced the research teams' perspectives on the relationship between education and rural transformation (particularly the agricultural research institutes involved), the question remained as to how to translate these findings into a national policy context.

The importance of informal learning. The study aimed to find out more about how young people learned new skills and knowledge for rural livelihoods. Findings from all three countries provided much evidence and new insights into the importance of informal learning - looking not only at what skills had been learned, but also how and why they learned certain knowledge and practices informally.

In Tounis village (Egypt) where male family members had gone for work in the town, young people learned much from their mothers as a respondent explained: "My mother taught me everything about farming, she is the source of inspiration to the whole family." They listed a wide range of skills that they had learned in this way: combating pests, seasons for farming and harvesting, transporting crops from the land to the house using a donkey or motorcycle, enhancing quality of crops, and using farming tools such as the axe, saw and plough. In Yabello, a pastoralist area in Ethiopia, respondents talked about how they had learned livestock rearing skills through starting with small animals like goats, then moving onto larger cattle. As one man explained, older members of the community were 'scaffolding' learning in quite a structured way: he learned to keep calves with older brothers and sisters at five years old, then at seven was allowed to keep calves along and looked after a large herd from the age of eight. Sake, an older pastoralist woman, summed up the knowledge and qualities that were needed: "To become cattle keeper/cow girl, it needs skills of knowing the place where the water and fodder is available in which season; it needs alertness; physical endurance to travel distant places and fight with wild animals and 
protecting cattle from attack." Significantly, older members of the pastoralist community (who gave such detailed accounts of informal learning) considered that schooling had interrupted this process of intergenerational knowledge transfer because their children were no longer working with the herds from this young age. In Cambodia (in Siem Reap, a popular tourist destination), young girls learned to weave pots for market through watching and copying their mothers weaving. They explained that they did not receive any explicit instructions nor would ask any questions but were corrected if they went wrong.

The research teams also found out about how people were learning new skills and knowledge from their peers. Some farmers in Ou Touch (Cambodia) described how they learned about new crop varieties 'secretly' through watching a family who had moved there from another province where vegetable growing had been dominant. They copied ideas that seemed to work, but did not ask questions of their neighbours. In Ethiopia, a respondent (who was unable to access extension services as he did not own land) had learned by chance from watching another farmer being instructed. He commented: "I remember one of the days on my way to the nearby market, I visited development agent showing fertilizer application method to a farmer on this land and I approached, saw and learnt how fertiliser could be applied when the method of sowing is in row." This data gave an insight into how informal and non-formal learning could be interconnected - this farmer had learned informally from observing the extension worker instructing another farmer. The cascade model of agricultural extension and farmer field schools involved both formal and informal learning as farmers observed and copied the 'model' farmers.

Informal learning of new skills and technologies was most widespread and effective when people perceived clear and immediate benefits. In Basona Werana (Ethiopia), eucalyptus was introduced by an NGO in 1979. Since then, despite the fact that there has been no formal support or training, every farmer has learned how to grow eucalyptus, how and when to harvest, what needs to be done to regenerate the stump. They recognised that eucalyptus could solve their problems of shortage of fuel and construction materials. Another example of spontaneous and wide-spread informal learning related to digital literacies. In all the field sites, young people had learned informally how to use mobile phones - regardless of whether they were literate or educated, female or male (though in Egypt only married women were allowed to use mobile phones in the communities researched). In Basona Werana (Ethiopia), young people explained how they had 
learned specific skills such as saving numbers with a contact name from friends who were literate and through repeated exercise of the procedure. In Yabello, non-literate respondents explained how they used visual symbols to acquire the skills of recognising who was calling and dialling, receiving calls, identifying numbers from contact list, opening the radio and saving numbers. Pictures of a butterfly, ball, dog etc. were used to save the phone numbers of different people so they could recognise who was calling. They also memorised the last two digits of a number as another way of recognising the call. A young pastoralist woman demonstrated how she could read numbers up to 5000 correctly on her phone, though she had never attended school and could not write down any numbers.

This kind of informal learning has been effective because people adapted the technology to their needs and developed their own strategies for use, such as working out visual symbols on the phone. They were also collaborating in their learning with literate peers who could help with the initial stage. In the latter case, the woman may have drawn on indigenous learning too. Borana pastoralists have traditionally taught their children to count numbers up to at least 100 when they start speaking - so that they develop the skills of counting and calculating money from the sale of cattle. Adopting a 'situated literacy' approach provided data on how non-literate people used literacy mediators (usually their relatives) and adapted literacies or numeracies to meet their needs. For instance, an older woman selling eggs explained that she checked her calculations with her grandson when she got home from market to ensure she was not cheated. If the change was not correct, she would then meet the buyer next market day and ask for the balance. It also emerged that traders in this area of Ethiopia had their own ways of making calculations easier by setting prices that were free from fractions.

The findings into informal learning processes within these communities offered understanding into the relationship between informal, non-formal and formal learning and the link with rural transformation. Sometimes people had resorted to informal learning in the absence of any formal instruction - for instance, in Cambodia, women relied on commercial traders of fertiliser and pesticides to give them individualised advice and support because there were no active extension workers in their area. In the case of digital literacies, young people just wanted to learn a specific skill or task that was easier to learn spontaneously from their peers than to seek formal training. Taking a gendered perspective on learning practices revealed that young women and men had different opportunities for learning soft skills informally - particularly 
in the Ethiopian pastoralist community where girls were not allowed to attend community gatherings after the age of ten.

In the project's national-level policy workshops with stakeholders, discussion focused on the gaps in formal provision that had forced people to engage in informal learning and seek alternative sources of knowledge. The findings raised issues around the criteria used for deciding who was included in extension or training programmes. There was also acknowledgement that providers needed to do more to build on people's informal learning strategies and existing knowledge while recognising that some practices may not enhance people's livelihoods in the long term (such as growing eucalyptus due to environmental concerns).

The symbolic value of schooling and rural transformation. A strong belief in the potential of schooling to open up new economic opportunities was evident in many of the interviews and focus group discussions held in all three countries. In all the field sites, many more of the younger generation had attended school than their parents, though there was evidence of the great financial burden that this entailed. For instance, in the highland Ethiopian community, a girl explained how she sold snacks on the road to finance her schooling. In the Egypt field sites, women described how they had had to give up school to work on the land, a source of regret for many older women as a respondent related: 'I wish I could have finished my school in order to get out of poverty, and that we do not have to accept living under my strict uncle who refused to make me continue my education'.

In discussions about what had been gained through going to school, young people talked more about the symbolic value of schooling than direct job opportunities or benefits - being seen as 'educated' bestowed status in their community. In the Ethiopia field sites, this was particularly so. A woman who had dropped out of school explained how she had bought and wore a watch so that people would think she was educated (even though she could not read the time). A pastoralist young man suggested that 'a schooled foolish person is better than unschooled clever person', going on to say that an illiterate person had no confidence and was more suspicious: if you're illiterate in current world, you do not understand what is going on and people do not understand you. This idea of schooled people having more confidence and communication skills hinted at the soft skills that might be learned informally through going to school. These comments were in sharp contrast to the older pastoralists who emphasised the value of traditional beliefs and practices over 
modern schooling, which was symbolised for them by reading and writing.

Although observation in the classroom or analysis of curriculum lay beyond the scope of this study, ethnographic research offered interesting insights into the meanings that people gave to schooling within these communities. The ambivalence expressed by some older people towards formal education (particularly in the pastoralist community in Ethiopia) related partly to the changing rural lifestyles and values of the younger generation, which they saw as connected to schooling.

From the policy perspective, the findings around schooling as a contested site pointed to the need to re-examine structures and approaches to formal education in order to respond to some of the constraints (in terms of time, resources and curriculum) that participants had identified. The three countries involved in this project were all actively engaged in the Education For All agenda, and were concerned to explore how their current programmes could be expanded to reach those who had been excluded or marginalized from formal education. This was particularly so in Egypt, where the project led to a government proposal for a new approach to adult literacy provision.

Changing values and livelihoods. There was a strong sense of rapid social and economic transformation in most of the rural communities researched, which had not necessarily improved poorer people's lives. Shrinking land resources made it difficult for young people to work as farmers independently so they were forced to work for their parents or as casual labourers. A young man in Basona Werana (the highland area, Ethiopia) explained that "it is very unlikely to get even a small plot of land from my parent's holding, leave alone from any other sources. " He had earlier dropped out of school to 'serve' his ageing grandparents in the hope of inheriting their land. In the Egypt field sites, young women who worked as agricultural labourers were similarly anxious to own their own land, as a respondent reflected: "I wish I own even one qarat ${ }^{2}$. I would be in heaven and fill the house with its food and blessings. "Similar emotions were expressed by an older woman in Yabello (Ethiopia) as she explained that pastoralism requires loving cattle, "without which it is difficult to bear the challenges. " These insights into people's affection for the land and animals suggested that farming/pastoralism was much more than just a job for them.

Life history accounts gave an insight into the ways in which livelihoods were rapidly changing. In Basona Werana (Ethiopia), local beverage trading 


\section{A. Robinson-Pant}

has become a major source of income for divorced young women as it requires only local materials and little capital. The women's stories revealed the risks of this occupation, with traders being subject to sexual abuse and even rape by their customers. Exploitation by employment agencies was also reported, where brokers demanded high fees to find young people jobs in hotels and cafes, which they were unable to repay. In many interviews, respondents spoke about their powerlessness due to a lack of voice. Describing the corruption in government cooperatives in Egypt, a farmer noted, "Farmers who own small plots suffer from injustice, but farmers who own 20 feddans the cooperative cannot rob him in the same way. In short, the poor has no place in this country.

These challenges to traditional livelihoods had been accompanied by changing social values, which older people in the pastoralist community in Ethiopia associated with school. Young people in the Ethiopian focus groups talked about a more individualistic attitude, described as 'free rider behaviour'. A young man explained how this made it difficult to work in group enterprises, "Because most youths in the group I belong are seekers of short term benefits and are not committed to execute responsibilities, they erode the spirit of working together and affect other members ' morale." These findings were particularly significant because many of the agricultural development inputs in this area were only available to young people who worked as a group, rather than to individuals.

Work for young people was much more than just a source of income. In Siem Reap, Cambodia, young women related how they preferred to work in local factories rather than in farming, even though the pay was no better. They enjoyed the social environment of the factory and the opportunity to meet their future spouses. It was evident that both women and men in this community put great importance on leisure activities. Young men said that they spent their free time drinking and watching Korean films in order to learn romantic phrases to try out on their girl friends when they chatted on their mobile phones at night. What emerged in all the studies was a sense that traditional values were being transformed as young people moved into new livelihood activities. Older people too recognised the limits of traditional knowledge and often supported their children to go to school, to move into new areas of economic activity or to migrate. The study revealed how rural areas were changing, and the ways in which people were engaging with such transformation - including developing new social spaces and identities.

Journal of Education and Research | March 2016, Joint Issue 5.2 \& 6.1 
Looking at the policy implications of these findings around changing values and identities, stakeholders at the national workshops again recognised the limitations of dominant development approaches and the need to engage with young people in particular in different ways. There was discussion about how the media, particularly TV, could begin to challenge and expose corruption and exploitation, as well as challenging attitudes.

\section{Education and Rural Transformation: Policy Interventions}

The aim of the IFAD-UNESCO study was not to evaluate policy and programmes in these areas of Cambodia, Egypt and Ethiopia. However, the findings suggested ways in which programmes might better respond to the educational needs and aspirations of young people in these areas and this became an important source of learning for those involved at central level in related sectors. The study included case studies of government, NGO and private providers of skill training and adult learning in the field sites in order to compare their approaches to learning and teaching.

In Cambodia, the research team investigated a private company's promotion of contract pig farming. Selected farmers were given all the necessary inputs, including individual training and support. This approach contrasted with the 'onesize-fits-all' approach observed in many NGO and government adult learning programmes - particularly in adult literacy. Within the pig-farming project, farmers were supported with their literacy needs as they arose, for instance, filling in forms and records. Non-formal literacy programmes in all three countries tended to adopt a functional literacy approach, teaching vocational skills and using literacy materials that were more generic, rather than tailored to the individual's needs. This resulted in local markets being saturated with certain products or skills, and literacy learning having little relevance to learners' everyday lives. The findings also suggested that there was more emphasis on hard skill than soft skill development - particularly in agricultural extension programmes. By contrast, respondents had emphasised the need to develop their skills of negotiation, confidence and marketing in order to be able to set up enterprises or deal with large landowners and companies coming into the area.

All three studies identified critical issues around targeting educational and agricultural programmes for young people, with particular policy implications for reaching the poorest groups. Young farmers in Ethiopia explained that they had been excluded from extension programme because they did not own land. Another 


\section{A. Robinson-Pant}

criteria for formal training courses was that young people should have completed school education. In Ethiopia, the team noted that non-formal training, if it existed for rural youths at all, required basic literacy skills as a precondition - which meant that the poorest youth were often excluded. The case study of contract farming in Cambodia revealed that the company preferred to target farmers from 30 - 50 years old because they had sufficient experience to run this kind of business (pig rearing). Within this age group, the company prioritised those under 40 years, as they were considered to be 'young, dynamic and less resistant to new techniques'. This commercial initiative proved highly successful in training farmers but indicated that younger people - particularly those without existing resources or experience - were not included in the scheme.

Analysing the ways in which the various providers supported learning for enhanced rural livelihoods, it was evident that the company valued the farmers' life experiences and prior learning, even if they lacked formal qualifications. This was in contrast to some of the NGO and government training programmes, which required formal educational experience. Policy analysis also revealed that 'youth' tended to be targeted as a homogeneous group, in stark contrast to the diverse experiences and livelihood strategies that young people related to the research teams in their life histories. Above all, although young and older respondents emphasised the importance of informal learning in their lives, the policy response to changing rural economies and communications infrastructure had been primarily to promote and expand formal educational initiatives.

\section{What Was Added to Policy Through Adopting an Alternative Lens?}

Overall, the research raised questions around how policy makers could better take account of and support informal learning. This was not just in terms of the skills and knowledge that young people acquired through everyday life, but also how to respond to their understanding of education and work as important spaces for developing social identities and relationships. Respondents in the study differed in how far they saw informal learning as a response to or as a result of transformation in these societies. What they shared in common however was a more holistic perspective on education and rural development than had been suggested in many policy debates in this area. The findings suggested that policy makers needed to adopt a non-linear approach to education and development, exploring what learning is already taking place and how rural areas are currently being transformed - rather than assuming that formal education alone can initiate 
change. The findings also challenged the dependence of educational policy on formal learning: people often found their own ways to learn the skills they needed or sought support from peers. Formal qualifications were required to access other kinds of learning - meaning that the poorest people were excluded from training opportunities. Schooling appeared to have a filtering function within these areas those who dropped out were unable to take up other opportunities either.

The holistic approach that young people took towards enhancing their livelihoods and learning contrasted with the tendency of many providers (NGOs, donor agencies and Government departments) and researchers to work largely within their own sector. The strong connections that respondents emphasised between off-farm and on-farm livelihoods contrasted with the divide between rural/urban and between different sectors, which is apparent in policy debates and research programmes. The findings suggested that educational and agricultural researchers needed to find ways of working more closely together in future to develop greater understanding of the synergies between formal and informal learning within rural transformation. Education is only one factor influencing rural transformation and greater collaboration across sectors is required to ensure that young people are able to take advantage of new livelihood opportunities in rural areas.

Taking a gendered perspective on education and rural transformation, it is clear that gender equality in access to formal education and training is still an important principle and has not yet been attained in all the communities where the research took place. However,

what also emerged was that informal learning is gendered too: community expectations about gender roles influenced the spaces where young women could develop confidence, decisionmaking skills and new professional identities. Although there was still a need to tackle the barriers faced by young women entering formal education, we realised that we could learn more about gendered responses to and the gendered impact of rural transformation through focusing on women's and men's experiences of informal learning in their communities and through migration.

\section{Conclusion}

This case study of the IFAD-UNESCO project has wider implications for educational researchers, policy makers and practitioners seeking to develop greater understanding of the complex relationship between education and rural transformation. Through making informal learning more visible to people 


\section{A. Robinson-Pant}

themselves and to educational providers/policy makers (the lower part of Tough's iceberg mentioned at the beginning of this paper), the research helped to broaden discussion about the relationship between education and social change. Although limited in scope (as a policy-commissioned and policy-focused study), the above findings point to the potential contribution that more rigorous in-depth ethnographic research could make in this important area.

This paper has taken a first step towards reconceptualising the link between education and rural transformation and challenging the dominant paradigm that has informed development policy and programmes to date. As we move towards the launch of the 2030 Sustainable Development Agenda (UN, 2015), it is particularly important to examine the assumptions about education and the kind of learning implied within the formulation of the various Sustainable Development Goals. Significantly, SDG 5 'Achieve gender equality and empower all women and girls' signals the role of 'enabling technologies' in promoting women's empowerment, implying an attention to informal as well as formal learning. Rather than assuming that education can initiate social change, I am proposing that we look at what we mean by 'education' and examine the ways in which rural areas have been and are being transformed. By considering formal education as only one aspect of learning in rural areas, we can then begin to develop a more complex and nuanced analysis. Our aim as educationalists should be to recognise, support and extend different kinds of learning, so that people gain the knowledge and skills to take greater control over their livelihoods in the face of rapidly changing rural economies.

\section{Notes}

1 The full report with literature review, details on methodology and research design and each country report can be obtained from UNESCO. See: http://uil.unesco.org/home/ news- target/ifad-unesco-study-reaffirms-the-importance-of-integrated-education-andlearning- for-rural-youth/ffe2640def243a6867d1bc250655a759/

2 Qarat is $1 / 24$ of a feddan, around $175 \mathrm{~m}^{2}$.

\section{Acknowledgements}

This paper draws on the IFAD-UNESCO project, 'Learning knowledge and skills for agriculture to improve rural livelihoods', in which I was involved as Global Research Coordinator. The project was directed by Subbarao Venkata Ilapavuluri, Bohrene Chakroun, Mari Yasunaga, and Keith Holmes 
from UNESCO Paris office; Maria Hartl and Rosemary Vargas-Lundius from IFAD, Rome. The country studies were conducted in collaboration with partner institutions by the following research teams:

o Cambodia (Council for Agricultural and Rural Development of the Royal Government of Cambodia) - Dr. Likanan Luch (Director), Mr. Kong Ratha, Mr. Huy Em, Ms. Srynith Lim and Ms. Sileak Guan

o Egypt (Ain Shams University in the Arab Republic of Egypt) - Prof. Dr. Moheb el Rafei (Director), Prof. Dr. Gehan Kamal, Associate Prof. Reda Abdel Sattar Mohamed, Dr. Omneya Nour Eddin, Ms. Nahla Gamal Mohamed

o Ethiopia (Ethiopian Institute of Agricultural Research of the Federal Democratic Republic of Ethiopia) - Mr. Kaleb Kelemu (Director), Mr. Alemu Sokora, Ms. Tiruwork Zelalem, Mr. Mekonnen Hailu, Mr. Tesfaye Haregewoin.

The country teams were supported by UNESCO colleagues, Mr. Santosh Khatri (Phnom Penh); Dr. Ghada Gholam (Cairo); Dr. Paul Mpayimana and Mr. Demelash Zenebe Woldu (Addis Ababa).

\section{References}

Barton, D., Hamilton, M., \& Ivanic, R. (2000). Situated literacies: Reading and writing in context. London, England: Routledge.

Colley, H., Hodkinson, P., \& Malcom, J. (2003). Informality and formality in learning (Report for the Learning and Skills Research Centre, Leeds, University of Leeds). Retrieved from http://www.LSRC.ac.uk

European Commission. (2001). Making a European area of lifelong learning a reality. Brussels, Belgium: Author.

Green, J., \& Bloome, D. (1997). Ethnography and ethnographers of and in education: A situated perspective. In J. Flood, S. B. Heath, \& D. Lapp (Eds.), A handbook of research on teaching literacy through the communicative and visual arts (pp. 181-202). New York, NY: Simon and Shuster Macmillan.

International Fund for Agricultural Development. (2010). Rural poverty report 2011. Rome, Italy: Author.

Lave, J., \& Wenger, E. (1991). Situated learning: Legitimate peripheral participation. Cambridge, England: Cambridge University Press. 
Lockheed, M., Jamieson, D., \& Lau, L. (1980). Farmer education and farm efficiency: A survey. In T. King (Ed.), Education and income (World Bank Staff Working Paper No. 402). Washington, DC: World Bank.

Polyani, M. (1967). The tacit dimension. New York, NY: Doubleday.

Rogers, A. (2000). Literacy comes second: Working with groups in developing societies. Development in Practice, 10(2), 236-240.

Rogers, A. (2014). The classroom and the everyday: The importance of informal learning for formal learning. Investigar Em Educacao, 1(1), 7-34. Retrieved from http://pages.ie.uminho.pt/inved/index.php/ie/issue/view/1/showToc

Street, B. V. (1995). Social literacies: Critical approaches to literacy in development, ethnography and education. London, England: Longman.

Tadele, G., \& Gelle, A. (2012, November). 'A last resort and often not an option at all': Farming and young people in Ethiopia. IDS Bulletin, 43(6).

Tough, A. (1979). Adults 'learning projects. Toronto, Canada: OISE.

United Nations. (2015, September 18). Transforming our world: The 2030 agenda for sustainable development. Retrieved from https://sustainabledevelopment. un.org/post2015/transformingourworld

UNESCO. (2014a). EFA global monitoring report 2013/4 - Teaching and learning: Achieving quality for all (Summary Report). Paris, France: Author.

UNESCO. (2014b). Reading in the mobile era: A study of mobile reading in developing countries. Paris, France: Author.

White, B. (2012, November). Agriculture and the generation problem: Rural youth, employment and the future of farming. IDS Bulletin, 43(6). 